\title{
La cosificación estética del deporte. El deporte como industria cultural desde la perspectiva de Theodor Adorno
}

\author{
The aesthetic objectification of sport. Sport as a cultural industry \\ from the perspective of Theodor Adorno
}

\section{José Luis Corbo* y Luis David Cal**}

\footnotetext{
* Licenciado en Educación Física (ISEF-UdelaR). Maestrando en Didáctica de la Educación Superior (Universidad CLAEH). Director coordinador de Educación Física del Consejo de Educación Inicial y Primaria (CEIP-ANEP).

$\triangle$-joselocorbo@gmail.com https://orcid.org/0000-00026076-3451

** Profesor de Filosofía (IPA). Maestrando en Didáctica de la Educación Superior (Universidad CLAEH). Profesor de Filosofía en bachilleratos de CES y CETP y en los colegios de los Hermanos Maristas y el Colegio Carlos Scaffo.

凶·davocal@hotmail.com https://orcid.org/0000-00026870-6785
}

RECIBIDO: . 19.9.2019

ACEPTADO: 7.11.2019

\begin{abstract}
Resumen
El presente ensayo se propone pensar el deporte en el contexto global actual; más precisamente, sus formas culturales y su devenir como producto histórico, desde la perspectiva crítica de su análisis estético. En ese marco, se plantea analizar al deporte, su génesis y sus transformaciones, conjuntamente con la crítica estética de Theodor Adorno, para finalmente articular ambas perspectivas. El trabajo se inscribe en clave educativa en relación con el objeto deporte, buscando enfrentarlo dialécticamente con su contradicción en la búsqueda de una tesis superadora.
\end{abstract}

Palabras clave: deporte, filosofía cultural, estética.

\begin{abstract}
This essay aims to examine sport within the current global context; more precisely, its cultural forms and its evolution as a historical product, from the critical perspective of its aesthetic analysis. Within this context, it aims to analyze sport, its genesis and its transformations, together with Theodor Adorno's aesthetic criticism, in order to finally articulate both perspectives. The work is inscribed in an educational key in relation to sport as the object, seeking to confront it dialectically with its contradiction in the search for an overcoming thesis.
\end{abstract}

Keywords: sport, cultural philosophy, aesthetics. 
[...] la cultura de masas no quiere transformar a sus consumidores en deportistas, sino en espectadores que gritan y jadean. Al retratar la vida entera como un sistema de competiciones deportivas francas u ocultas, la cultura de masas entroniza al deporte como la vida misma, y aún elimina la tensión entre el domingo deportivo y la semana miserable, en la cual radica la parte mejor del deporte real. Esto es el resultado de la liquidación, en su seno, de la apariencia estética».

Adorno y Horkheimer, Dialéctica de la ilustración, 2016.

\section{Introducción}

Pensar el deporte actual supone como desafío deconstruir sus formas, trascender su práctica como mero espacio de contienda para tensionar su valor de cambio como objeto de consumo. Esta configuración actual, que transforma al deporte en mercancía y que, por tanto, mercantiliza su consumo, ha sido objeto de numerosos análisis. Se trata de las formas de un «deporte» que se compra y se vende, que adquiere significaciones singulares hasta el punto de lograr construcciones estéticas diversas, que terminan por deportivizar las relaciones de los sujetos, quienes parecen habilitados a transformar todos los escenarios de la vida en verdaderos estadios deportivos.

Podemos entender que el deporte no es la vida y que la vida no es deporte, y que este último es, a su vez, víctima de las formas y deformaciones que se configuran sobre él. Para Theodor Adorno, todo elemento de la cultura es un producto histórico reflejo de la realidad objetiva. La cultura, como superestructura, es la representación de la estructura enmarcada en la producción y sus relaciones. Por lo tanto, la cultura se produce cual mercancía, y existirá necesariamente una industria de producción de cultura, cuya válvula de regulación no será otra cosa que el propio mercado.

En tal sentido, el presente texto pretende desnaturalizar lo cultural desde la perspectiva emancipatoria de Habermas (1986), asociada a un nivel de análisis capaz de discriminar lo natural de lo culturalmente naturalizado. Apelamos a un análisis crítico del deporte, orientado a comprender sus formas, de modo que habilite a los agentes que sobre él actúan a su posterior transformación, pensándolo como práctica culturalmente heredada y necesariamente accesible a todos los sujetos. Entendemos que cualquier proyecto educativo que involucre al deporte como objeto de enseñanza deberá ir más allá de su propia práctica y creemos, por tanto, que comprender los sentidos implícitos de su construcción estética será parte fundamental de ese recorrido. 


\section{Origen y estética histórica del deporte}

Si bien existen manifestaciones que podrían vincularse al deporte desde los orígenes civilizatorios — como el atletismo griego retomado por Pierre de Coubertin-, el deporte al que haremos referencia nace de la escuela deportiva inglesa de Arnold del siglo XVIII.

Será preciso remitirse a los juegos populares ingleses hasta el punto de pensar la génesis deportiva como la expresión perfeccionista de aquellos modelos originales, basados en artesanales reglamentos con fondos ideológicos, que lo constituyeron y potenciaron en el resto de Europa y, posteriormente, en el mundo globalizado.

La expresión libre y autónoma de aquellos juegos cedería terreno ante el orden y el disciplinamiento que proponía el deporte como actividad pensada para un determinado sector social y manipulada al servicio de la reproducción de ciertas estructuras hegemónicas de poder.

En efecto, no solo se trataba de que los alumnos desarrollaran cualidades propias de dirigentes, como coraje, virilidad, liderazgo, espíritu de equipo, que tienen una función y un significado muy diferente para los hijos de la aristocracia y de la alta burguesía, que para los hijos de los agricultores o tenderos. También se trataba de que adquirieran maneras y formas de conducta propias de su clase, como el rol de la distancia que da lugar a una actitud a mantener en todos los papeles para los que los futuros líderes fueron designados. (Velázquez Buendía, 2004, p. 174)

De igual forma y como parte del mismo proceso, los deportes ingresaron a las escuelas públicas inglesas -espacio educativo selecto de la aristocracia y burguesíacomo aparato válido de manipulación y adoctrinamiento, orientado a calmar el jolgorio y limitar los excesos de los jóvenes, así como a reducir su potencial revolucionario.

En esa línea, y como parte de un proceso común, los reglamentos se universalizaron como eje constitutivo esencial, reproduciendo en su lógica interna las mismas condiciones que esa clase social consideraba indispensable promover. Ese ingreso al diseño curricular de aquellos tiempos, y su potencial reproductor del orden social de esa Inglaterra y de quienes accedían a las políticas educativas de la época, adjudican al deporte de hoy un valor educativo intrínseco. Es decir, su enseñanza se justifica mediante perspectivas axiológicas que atribuyen al deporte un valor moral propio, relativo en su génesis a las formas de la moral burguesa.

Jean Marie Brohm (1982) analiza el deporte moderno desde esa perspectiva presuntamente marxista, pero asignándole rasgos funcionalistas, al servicio de un sistema de reproducción que encontraría concordancia con una particular interpretación de Althusser y sus aparatos ideológicos (Althusser, 2005). No obstante, esa interpretación es 
rechazada por el propio Althusser, quien toma distancia y escribe su propia defensa (Althusser, 2015) alegando que esa lectura de Marx, así como la respectiva interpretación de sus propios escritos marxistas, desconocen la dialéctica como posibilidad de negación, algo que él nunca tuvo intención de hacer.

El capítulo final del texto más importante de Brohm (1982) se titula «El deporte como aparato ideológico del Estado», donde sostiene su poder como construcción superestructural. En esa lógica discursiva, si el Estado es funcional a la clase dominante y el deporte funcional al Estado, su valor como aparato de dominación sería incuestionable, a riesgo de caer en una suerte de estructuralismo/funcionalismo no pasible de ser superado desde una perspectiva dialéctica marxista.

En relación con el origen del deporte y su justificación ontológica (Elias y Dunning, 1992) entienden que el origen del deporte es previo a las formas propias de la escuela inglesa. Pare ellos nace de la mano del proceso civilizatorio, sostenido sobre su eventual potencial para la «adquisición de valores necesarios para la cohesión social», lo que refiere a la intención inmanente de controlar el tiempo de ocio de los sujetos mediante la instalación de ciertas prácticas presuntamente deseables.

Siguiendo entonces con el recorrido histórico, vemos que, a medida que el deporte se desarrolla, nacen a su vez las instituciones que se encargarán de regular su funcionamiento a escala global, las federaciones deportivas, las cuales excluyen las prácticas lúdicas agonísticas no federadas.

Más allá de los significados que ha adquirido como práctica y su expansión incuestionable como legado cultural en el devenir del mundo globalizado, el deporte ha logrado una magnitud innegable como objeto de consumo, que vuelve a acercarlo a aquellos que en un momento estuvieron alejados de la práctica como tal.

El deporte, que nació de juegos realmente populares, es decir, producidos por el pueblo, regresa al pueblo a la manera de la música folclórica, en forma de espectáculos producidos para el pueblo [...] se difunde mucho más allá del círculo de los que lo practican actualmente o lo hicieron en otra época, es decir, entre un círculo que no siempre tiene la competencia para entenderlo como es debido. (Bourdieu, 1990, p. 149)

Para Bourdieu, el deporte moderno como construcción de la clase obrera, como producto del pueblo trabajador expropiado por los nobles ingleses, regresa al pueblo en forma de espectáculo. Aquellos sujetos colonizados que entregaron su legado al sector más pudiente para educar a los jóvenes en sus escuelas, en determinado momento de la historia vuelven a participar en él como espectadores.

El problema es que las formas que había adquirido el deporte habían alejado al pueblo de la propia práctica deportiva, con lo que también lo alejaron de la comprensión 
de las formas deportivas más profundas, del virtuosismo técnico y táctico sobre las acciones, del entendimiento de las lógicas profundas que hacen del deporte un objeto en extremo complejo y perfectible. Le habían quitado al pueblo la capacidad para entender el deporte, vinculada siempre a su participación y comprensión, por tanto, del juego desde el juego.

Esta suerte de robo intelectual construyó un sector social que participa como espectador, pero que aplaude la teatralización del deporte en sus aspectos más bárbaros. Se legitiman las formas de entrega, lo violento por sobre lo virtuoso, lo pícaro por sobre lo estratégico..., en fin, lo antideportivo por sobre lo estrictamente deportivo, de forma de que el deporte, en función de su imposibilidad de escapar a los aspectos exógenos que lo construyen, sufre innumerables deformaciones dentro y fuera de la cancha.

Hoy en día, el espectáculo deportivo se ha transformado en una suerte de espacio de catarsis, en una representación de la expresión —en un espacio falsamente construido- de los problemas reales que se suceden en el mundo material, en las relaciones objetivas entre personas.

Se deforma, para el caso, la estética deportiva.

\section{La crítica estética de Theodor Adorno}

Adorno fue uno de los representantes más destacados de la Escuela de Frankfurt. La presunta ortodoxia de la que muchas veces fue acusado Max Horkheimer logra tal vez en Adorno el equilibrio que la Escuela requería, dadas las condiciones y necesidades históricas. Su obra fue marcada por la complejidad oscura de la intelectualidad alemana, en textos de un nivel de abstracción y una profundidad destacables. Su calidad de filósofo y músico delimita una relación muy estrecha con su interpretación del arte y con un análisis estético sobre las formas particulares que había adoptado en Europa y en la Alemania nazi.

Para Adorno, era necesario denunciar la pérdida de expresión creativa del artista y su degradación como expresión de una conciencia colectiva, de una consciencia cosificada. La masificación en torno a construcciones estéticas poco menos que industriales demarca el auge de formas artísticas que cobran necesariamente valor en el mercado en función de su predisposición estructural para el consumo. Estas formas estéticas adquieren rasgos de superficialidad, de liviandad, y se dibujan en torno de aquello que se ve, de lo percibido por los sentidos, olvidándose de lo subyacente, de lo oculto, de los sentidos implícitos en la obra.

Factores cada vez más numerosos fueron arrastrados por el torbellino de los nuevos tabúes, y los artistas sintieron menos alegría por el nuevo reino de libertad 
que habían conquistado y más deseo de hallar un orden pasajero en el que no podían hallar fundamento suficiente. Y es que la libertad del arte se había conseguido para el individuo, pero entraba en contradicción con la perenne falta de libertad de la totalidad. (Adorno, 1983, p. 19)

El gran olvidado del arte del siglo XX, para Adorno, es el artista, que se transforma en productor de mercancías para la industria cultural. El arte pasa a ser una construcción al servicio de los potenciales consumidores y deja de representar la expresión del artista. Será lo que el consumidor necesita consumir y no lo que el artista necesita expresar. Esto altera la tradicional forma de establecer relación con la obra de arte.

Desde la perspectiva de Adorno, la vinculación con el arte siempre fue la admiración; se reconoce que las obras de arte son admirables en sí mismas y no solo para el sujeto que las contempla. La relación con el arte no suponía una posesión, sino lo contrario: el sujeto no poseía a la obra de arte, sino que desa parecía en ella. Antes de la total manipulación de la mercancía artística, el sujeto debía olvidarse de sí mismo y perderse en la obra. La identificación a la que tendía como ideal no consistía en igualar la obra de arte con él, sino en igualarse él a la obra de arte.

En cambio, la industria de la cultura trabaja de otra manera y exige o impone otra relación: la obra de arte será considerada un mero vehículo de la psicología de quien la contempla, y todo aquello que la obra de arte cosificada ya no puede decir lo sustituye el sujeto por el eco estereotipado de sí mismo que cree percibir en ella.

La industria de la cultura hace aparecer el arte como algo que es cercano al hombre, algo que lo obedece (Del Rey Morato, 2004). Si lo existente fagocita los productos artísticos que se habían alzado, para negarlos los transforma en objeto de consumo. Se trata de una emancipación garantizada por la técnica, que refleja la más fraudulenta forma de totalitarismo y conformismo, en la que confluyen la televisión, los periódicos y el espectáculo. La tarea del arte es para Adorno desmontar este engranaje, impedirlo, o al menos demostrar la posibilidad de hacerlo (Givone, 1999).

Si bien en las primeras ediciones de La industria cultural, la gran obra de Adorno y Horkheimer, no aparecen alusiones directas al deporte y su enfoque es esencialmente sobre la industria del arte, las últimas ediciones anexan los apuntes póstumos que los autores no llegaron a publicar. Es ahí donde encontramos las primeras referencias a las formas que el deporte espectáculo comenzaba a adquirir y las formas en que la industria cultural se apropiaba de él para transformarlo en una mercancía más.

Para los autores, el deporte era una representación más del mismo producto, y las sociedades del capitalismo tardío hacían de él a su antojo, despojándolo de sus formas originales, de su valor estético autónomo.

Más allá del análisis del producto global del deporte, es decir, de la construcción histórica de la práctica y sus espectadores, del producto de consumo, el análisis 
dialéctico minucioso que acostumbraba a realizar Adorno con la obra de arte es claramente transferible al deporte actual.

\section{La perspectiva dialéctica de Adorno y su transposición en el deporte}

En su acercamiento con Walter Benjamin, Theodor Adorno adoptó no solo sus formas lingüísticas, sino que trabajó sus ideas considerando sus reconstrucciones dialécticas y agregándoles rasgos propios, los que terminarían separándolos conceptualmente:

Adorno podía apreciar que el método del Trauerspiel ${ }^{1}$ era «inmanente» no solo en su rechazo a transcender el reino de los elementos fenoménicos (y de allí su «exactitud») sino también en su relación dialéctica con la historia de la filosofía. Porque su originalidad no se lograba ignorando el pasado, sino transformando conceptos tradicionales, invirtiendo dialécticamente sus relaciones y desafiando las consignas de la «segunda naturaleza». (Buck-Morss, 1981, p. 199)

Para Adorno, era imprescindible el enfrentamiento dialéctico de una segunda naturaleza - lo percibido, lo fenoménico - con su primera naturaleza - la realidad material, objetiva-, lo que construía la historia real de la filosofía. Esa perspectiva de análisis de lo irreal y lo real se constituye como dispositivo de análisis del mundo, tomando como eje el acercamiento necesario entre lo abstracto y lo concreto.

Su estética pone en evidencia las complejas relaciones entre la obra de arte y la realidad, mediante una dialéctica viviente que se ocupa de dichas relaciones: relaciones entre forma y contenido, entre subjetividad creadora y objetividad social, entre el historicismo de la creación artística y el carácter suprahistórico de la obra creada. Es una estética que pone en relación una dialéctica de opuestos, de lo que resulta un proceso de cristalización del devenir, de la materialización de la conciencia, de la manifestación en la obra de arte de la experiencia estética (Rinaldi, 2006). El arte no es ya el reflejo de la realidad sino su negación, que es precisamente la vía de diálogo con lo real, en tanto en esta negación se manifiesta el cambio que aún no se ha producido en la sociedad.

En Adorno, el arte se propone como paradigma de la razón no identificadora. Dado su carácter autónomo, la obra de arte no necesita identificarse con nada ajeno a ella misma. Es la conciencia de lo no idéntico en cuanto no precisa identificarse ni ser identificada con concepto alguno para existir en el plano ontológico (Blanco, 2016). Este modernismo de «la autodestrucción creadora», de «la negación del orden estable» o «la 
revolución de la esfera estética» los artistas lo llamaron «la otra modernidad». Se trata de un acto de rebeldía contra el orden, el academicismo y la tradición del pasado en busca de la renovación (Valdes Sampedro, 2019).

Adorno se preocupó esencialmente por rescatar en sus análisis aquello que pocas veces se observaba de las manifestaciones artísticas y su construcción, y enfrentarlos con su negación en la realidad objetiva.

Cada ensayo de Adorno articula una «idea» en el sentido benjaminiano de construir una constelación específica y concreta a partir de los elementos del fenómeno, de manera que la realidad sociohistórica que constituye su verdad se torne físicamente visible en su interior. (Buck-Morss, 1981, p. 203)

Acercándonos a su análisis y llevándolo al deporte particularmente y a las formas que este adquiere en la cultura del consumo, donde su origen clasista y reproductivista trasciende para transformarse en mercancía, estamos habilitados a su reconstrucción dialéctica con la estructura, con la realidad objetiva, tal como proponía Adorno en algunos de sus ensayos.

Todo aquello visualmente apreciable en una segunda naturaleza (el mundo alienado y vacío de significado de Lukács) esconde dialécticamente la verdad objetiva desde su real correspondencia en su conjunto histórico, en el escenario deportivo y en las manifestaciones de los sujetos individuales/colectivos. El arte tiene la obligación de no quedarse en la observación de la superestructura, (mitificación burguesa), sino que debe llegar con su penetrante mirada a la estructura económico-social y captar la dialéctica histórica que constituye la verdadera realidad. El criterio artístico sería el de totalidad (Plazaola, 1973).

El espectáculo deportivo presenta una ubicación donde los espectadores determinan la dialéctica de la representación. Los palcos son ocupados por aquellos que simulan tener el poder sobre el espectáculo, pero que, contrariamente, no son más que la primera víctima del dominio de las industrias que produce el propio espectáculo. Su poder es no poder en relación con el poder real. La clase masiva, el espectador medio, se siente libre como parte del espectáculo, pero esa libertad no es más que un ser parte de un fenómeno de enajenación. En ningún lado se siente más libre que en el lugar en el que está más preso o apresado por un inconsciente colectivo.

El lugar en que el espectador pretende ser más él, donde siente que cada deportista juega para él, para que la felicidad del triunfo sea suya — un claro producto de la industria cultural del deporte espectáculo- es el lugar del no ser para sí mismo, sino ser para el propio espectáculo.

Decía Adorno — citado por Buck-Morss (1981, p. 212)—con relación a la música: 
El hombre al que pueda metérsele en la cabeza que algo está allí especialmente para él y que por lo tanto comprara la canción, desde ese momento ya no podrá caer en el error de pensar que le pertenece [...] Él pertenece al producto, y no a la inversa. Si quisiera cambiar algo lo encerrarían, es decir, si no estuviera ya encerrado.

El fenómeno del deporte espectáculo, en ideas de Adorno, solamente podría desenmarañarse mediante el análisis dialéctico de sus opuestos. Aun el deportista virtuoso, que intenta defender en palabras su libre expresión en relación con el juego, es la representación dialéctica de la expresión autodeterminada bajo las formas estrictas del rendimiento exigido.

La primera naturaleza es solamente perceptible en las relaciones económicas que configuran dialécticamente la segunda naturaleza. Dicho de otra forma: todo aquello que se observa en la segunda naturaleza del deporte espectáculo es la representación dialéctica de las relaciones económicas que subyacen a la industria de la cultura deportiva. La realidad objetiva es dialécticamente negada por su representación alienada y alienante.

El deporte como espectáculo de masas define un estar totalitario que utiliza principios de organización fabril para la producción de bienes intangibles como valores, ideologías, contenidos simbólicos, pautas de conducta y costumbres. El deporte como espectáculo artístico contribuye a consolidar la industria cultural, que es la industria del entretenimiento. Esta diversión promovida tiene un aspecto negativo, ya que implica una adhesión al estado de cosas. Divertirse implica estar de acuerdo (Amoruso, 2008).

Para Adorno las obras de arte deben ser enigmas, y es por ese carácter que ejecutan un doble movimiento, en el que convive cierta contradicción: se dice algo, y a la vez se lo oculta, se manifiesta alguna cosa, pero no se termina de enseñarla. Es por ese carácter enigmático que los individuos que están instalados en el principio de realidad son incapaces de la admiración de la experiencia artística.

El arte tiene el poder de resistir a esa compacta mayoría que se ha convertido en criterio de la cosa y de su verdad social. El criterio central es su fuerza de expresión, en un gesto sin palabras; una expresión de heridas sociales que consigue poner en evidencia la falsedad de un estado social (Del Rey Morato, 2004). El arte está ligado a la negatividad, a la desarticulación con ese lenguaje que se ha hecho cómplice de la real manipulación por los medios de comunicación e instrumentalizado por el poder económico y social (Givone, 1999).

El deporte espectáculo — tal el arte en Adorno- pierde su autonomía estética en función de sus formas cosificadas, de lo que se hace de él para la masa consumidora. Su representación estética supera su carácter intrínseco y se desdibuja dialécticamente con su segunda naturaleza. 


\section{Superación dialéctica del deporte espectáculo: la negación de la negación}

El deporte actual, transformado en mercancía y construido al servicio del mercado, ha perdido la autonomía estética representada en el carácter interno del virtuosismo de la práctica. Aquella libertad que el movimiento deportivo significaba queda presa del condicionamiento estructural de la primera naturaleza, de las relaciones económicas que la construyen.

La construcción estética del deporte actual trasciende al objeto, parece superarlo, negarlo bajo las formas de la exteriorización psicológica de la conciencia colectiva. El deporte que se aprecia es el deporte que exige la necesidad generada estructuralmente.

Tal vez el ejemplo más representativo sea el Mundial de fútbol, magnificación de una estructura de consumo que supera el fin en sí mismo del espectáculo — tal su génesis- y localiza sus fines en su valor de cambio, en su mercantilización, generando un producto estético que invade el universo de las comunicaciones y que suspende al mundo por un tiempo, alejando a los sujetos de la realidad material.

La tesis afirmativa del deporte original, su potencial estético, se enfrenta a la negación de la estética del consumo, del producto industrialmente pensado. Su superación dialéctica representará un estado superior de las cosas en el que ambas tesis convivan, superadas dialécticamente. Parece complejo pensar una superación desde la estructura, desde las relaciones económicas que regulan las formas del deporte, así como el retorno a la esencia deportiva de la estética del virtuosismo.

La idea de superación en Adorno se construye mediante la revolución de la superestructura marxista, de las formas de la doctrina ideológica, generando un estado de cosas en el que el acceso a la admiración de sus formas parezca al alcance de sus espectadores - de la masa consumidora-, los que deberán ser capaces de acceder a su primera naturaleza oculta, de comprender las relaciones económicas que subyacen bajo las formas del deporte que consumimos.

Es necesario que la práctica deportiva recupere su potencial estético, su virtuosismo autónomo, fragmentado y admirable, no reductible a una estructura ideológica. Se trata, en definitiva, de una práctica espontánea y distanciada, pasible de valoraciones nuevas, que permite emerger una objetividad de cambio de consciencia que terminará en un cambio sobre la realidad objetiva.

Esta práctica deportiva genuina permitirá suscitar algo que no exista, y en la aparición de ese algo inexistente como si existiese es donde radica su potencia. Se trata de un hacer consciente lo universal que late en lo singular, pero en una nueva relación, que no es, de ningún modo, una mera imitación. Para no ser un reflejo de la estructura 
dominante, la práctica deportiva deberá generar una experiencia de sublimación estética tal que el sujeto, al contemplarla, se pierda en su admiración.

Entendemos entonces que el valor educativo del deporte — dada las necesidades emancipatorias actuales- trasciende las formas de la comprensión del hecho deportivo como práctica neutra y creemos que la esencia de una educación como praxis se construye desentrañando sus sentidos reales desde su vínculo con la realidad objetiva. El análisis estético y la teoría estética de Adorno nos aportan herramientas esenciales para ese eventual análisis.

\section{Bibliografía}

Adorno, T. (1983). Teoría estética. Buenos Aires: Orbis.

Althusser, L. (2005). La filosofía como arma de la revolución. México: Siglo XXI.

Althusser, L. (2015). Introducción a la filosofía para no filósofos. Buenos Aires: Paidós.

Amoruso, N. (2008). Una revisión al análisis de Theodor Adorno sobre el jazz. A parte Rei: Revista de Filosofía, 55, 2-14.

Blanco, A. (2016). La herencia de la estética frankfurtiana en el pensamiento de Michael Foucault. Sociocriticism, 31(1), 13-17.

Bourdieu, P. (1990). Sociología y cultura. México: Grijalbo.

Brohm, J. (1982). Sociología política del deporte. México: Fondo de Cultura Económica.

Buck-Morss, S. (1981). Origen de la dialéctica negativa. México: Siglo XXI.

Del Rey Morato, J. (2004). Adorno y la crítica de la cultura de masas. CIC: Cuadernos de Información y Comunicación, 9, 41-67.

Elias, N. y Dunning, E. (1992). Deporte y ocio en el proceso de la civilización. México: Fondo de Cultura Económica.

Givone, S. (1999). Historia de la estética. Madrid: Tecnos.

Habermas, J. (1986). Conocimiento e interés. Madrid: Taurus.

Plazaola, J. (1973). Introducción a la estética. Madrid: Biblioteca de Autores Cristianos.

Rinaldi, M. (2006). El concepto de autonomía del arte en la Teoría Estética de Adorno. (Tesis de grado). Universidad de Buenos Aires, Facultad de Filosofía y Letras, Buenos Aires.

Valdes Sampedro, O. (2019). El rock y la modernidad: hacia una nueva experiencia. Recuperado de http://web.uaemex.mx/plin/colmena/Colmena\%2061-62/Aguijon/OVS.html

Velázquez Buendía, R. (2004). Enseñanza deportiva escolar y educación. En J. L. Hernández, Didáctica de la Educación Fïsica. Una perspectiva crítica y transversal (pp. 171196). Madrid: Biblioteca Nueva. 